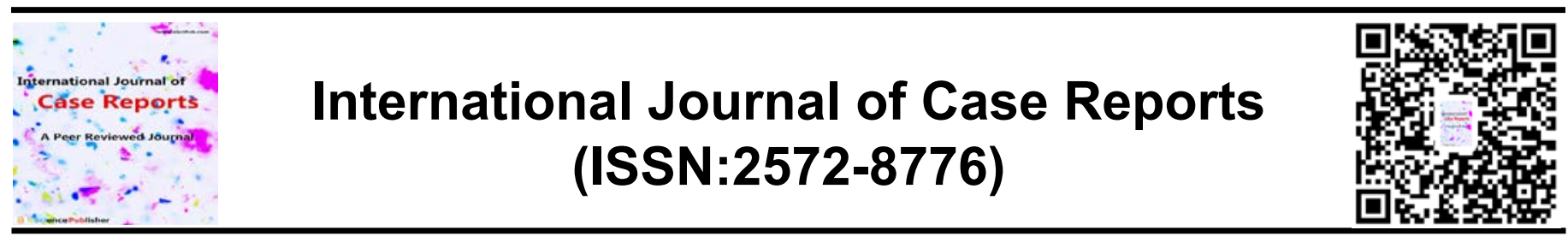

\title{
Twins With Endogenous Tinea Versicolor
}

\section{Alen J Salerian MD}

Organisation: Modern Psychiatry; Adress:8 Zaimi street,paleo falero,Athens 17562,Greece

\section{Identical Twins with Endogenous Tinea Versicolor}

This case report was inspired by recent medical data consistent with the obser-vation that Tinea Versicolor caused by Malassezia Furfur species may be en-dogenous produced by human body.

This case report involves a pair of identical twins -ages 71- who have had recur-rent Tinea Versicolor infections for over six decades.

The author of this article twin A, a physician and his brother twin $B$ have in summer months had skin lesions - on chest and upper extremities of round ap-proximately 1 inch wide - diagnosed as tinea versicolor by many doctors in diverse medical settings in different countries since their adolescence. The infec-tions have been successfully treated by antifungal medications.

Both twins were born in Istanbul Turkey. Twin A who lives in Houston Texas had lived in Los Angeles California and Dahran Saudi Arabia. Twin B who lives in Athens and spent the majority of his adult life in Washington DC. Neither twin reported any association between location and tinea versicolor infections yet they both observed that almost always infections emerged in warmer climates.

Both twin $A$ and twin $B$ have been diagnosed with hypertension and hypercho-lesterolemia well controlled by amlodipine $10 \mathrm{mg}$ and atorvastatin $20 \mathrm{mg}$ respectively.
*Correspondence to Author: Alen J Salerian MD

Organisation: Modern Psychiatry; Adress:8 Zaimi street,paleo falero,Athens 17562 , Greece

How to cite this article:

Alen J Salerian. Twins With Endogenous Tinea Versicolor. International Journal of Case Reports, $20194: 81$

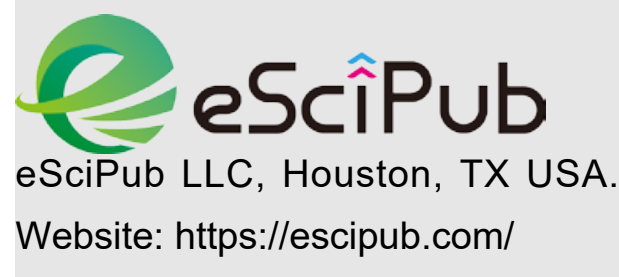




\section{Observations Consistent with Endogenous Origin of Malassezia Yeasts}

A. Malasezia Furfur are not not contagious (1).

B. Human genetics. -independent of immune competence - govern Malassezia furfur infections (1).

C. Inoculation of Malassezia yeasts into human skin without occlusion does not cause infection (2).

D. Infants skin is colonized by malassezia furfur in the first month (3) although amniotic fluid does not harbor malassezia furfur (4), neonate' skin at birth contains no Malassezia Furfur (5) and Malassezia furfur are not contagious (1).

E. Sera of people with malassezia infection and healthy people with skin colonized by malassezia do not show any difference in antigen titers of malassezia (6).

\section{F. Malassezia furfur and humans have coevolved (6).}

Although the precise mechanism and pathways of endogenous production of Malassezia furfur yeasts is unknown yet the certainty of their endogenous origin seems to very high. This is because six independent bidirectional influences are associated with endogenous Malassezia furfur infections. This observation Is further reinforced by recent molecular discoveries which suggest amniotic fluid (7), placenta (8), breast tissue and milk which had previously thought to have been sterile are not sterile and breast tissue and milk bacteria are not contaminants (9).

In summary this case report of identical twins with Malassezia Furfur infections provides clinical evidence in support of the endogenous origin of Tinea Versicolor infections. This novel observation raises the possibility that some infections currently attributed to foreign microorganisms may indeed be endogenous and result from humans. Of importance it may be prudent to investigate whether burn wound and opportunistic infections that are attributed to foreign invading microbes are endogenous infections.

\section{References:}

1. He S.M., Du W.D., Yang S., Zhou S.M., Li W., Wang J., Xiao F.L., Xu S.X., Zhang X.J., October 2007. The genetic epidemiology of tinea versicolor in China. Mycosis/ volume 51/ issue one.

2. Faergemann J.,Aly R., Wilson D.R.,Maibach H.I.,; Skin occlusion : effect on Pityrosprum orbiculare,skinP$\mathrm{CO} 2$,ph, trans epidermal water loss, and water content. Archives of dermatological research. November 1983, volume 275, issue 6, pages 383-387.

3. Powell D, Hayes D, Durell D E, Miller M , Marcon M $J$, August 1987 ,Malassezia furfur colonization of infants hospitalized in intensive care units. The Journal of pediatrics, volume 111 , issue 2 , Pages 217-220.

4. Capone K. A., Dowd S.E., Stamatas G.N., Nikolovski J., Diversity of the human skin microbiome early in life.J Invest Dermatolo ,2011.131(10)206-2032.

5. Digiullo D.B., .Diversity of microbes in amniotic fluid. Seminars in fetal and neonatal medicine. Volume 17, issue 1, February 2012 pages 2- 11.

6. Faergemann J., Antibodies to Pityrosporum orbiculare in patients with tinea versicolor and controls of various ages , Journal of Investigative Dermatology, 1983 Feb;80(2):133-5

7. Jimenez E.,Marin M.L.,Matin R., Odriozola J.,M.Olivares M.,Xaus J.,Fernandez L.,,Rodriguez J.M., Is meconium from healthy mothers sterile? Research in Microbiology.(2008).159,3,187-189.

8. Stout,M.J.et al. Identification of intracellular bacteria in the basal plate of the human placenta in term and preterm gestations. American Journal of obstetrics and gynecology 208, 1 - 7 2013).

9. Urbaniaak,C. Cummins J, Brackstone $M$, Macklaim J M, Gloor G B, Baban C K, Scott K ,et al. 2014. Microbiota in human breast tissue. Appl.Environ. Microbiology 80, 3007 - 3014.

10. Cabrera-Rubio R., Collado M.C.,Laitenen K., Salminen S., Isolauri E.,2012, The human milk microbiome changes over lactation and is shaped by maternal weight and mode of delivery. The American Journal of clinical nutrition volume 96, issue 3 , September 2012, page is 544 four four551.

11. Gaitanis G, Velegraki A, Alexopoulos EC , Kapsanaki-Gotsi E, Zisova L, Ran $Y$,Zhang $\quad H$, Arsenis $\quad G$, Bassukas ID , Faergemann $\mathrm{J}$ Malassezia furfur fingerprints as possible markers for human phylogeography. The ISME Journal [20 Nov 2008, 3(4):498-502]. 